\title{
RISKY BEHAVIOURS AMONG YOUNG ELITE-STUDENT-ATHLETES
}

\author{
Results from a Pilot Survey in South-Eastern France
}

(Article paru dans : International review for the sociology of sport,2004, vol. 39, n², pp. 233-244)

\section{Patrick Peretti-Watel,}

Regional Centre for Disease Control of South-Eastern France (ORS PACA), and INSERM Research Unit 379, 'Social Sciences Applied to Medical Innovation', Institut Paoli Calmettes.

Address: P. Peretti-Watel, ORS-PACA INSERM U379, 23 rue Stanislas Torrents, Marseille, France.

\section{Valérie Guagliardo,}

Regional Centre for Disease Control of South-Eastern France (ORS PACA), and INSERM Research Unit 379, 'Social Sciences Applied to Medical Innovation', Institut Paoli Calmettes.

\section{Pierre Verger}

Regional Centre for Disease Control of South-Eastern France (ORS PACA), and INSERM Research Unit 379, 'Social Sciences Applied to Medical Innovation', Institut Paoli Calmettes.

\section{Jacques Pruvost}

Regional and Departmental Authority on Youth and Sports of South-Eastern France (DRDJS PACA), Marseille, France.

Patrick Mignon

Laboratory of Sociology of Sport, National Institute for Sport and Physical Education (INSEP), Paris, France.

\section{Yolande Obadia}

Regional Centre for Disease Control of South-Eastern France (ORS PACA), and INSERM Research Unit 379, 'Social Sciences Applied to Medical Innovation', Institut Paoli Calmettes.

\section{Abstract}

Since the end of the 1980s, 'youth risky behaviours' have become a major issue for public health. The relationship between these behaviours and sporting activity is well-documented but still controversial. This article examines some sociological hypotheses related to this relationship, with data from a pilot survey conducted on a sample of 458 elite-student-athletes (ESAs) aged 16-24, gathered and trained in specialized public centres. We found a significant relationship between motives to do sport and 'risky behaviours': ESAs who considered sport as a convivial leisure were more prone to use cannabis, while ESAs who mingled sporting and extra-sporting achievements together were more likely to engage in risky behaviours on the road, possibly because they transposed values from the sporting field (speed, competition) into the 'real world'. Moreover, sporting activity may provide opportunities for drug use with peers as well as incentives to use drugs in order to cope with the anxiety induced by high-level competition. Thus 'recreational' drugs may be used as 'integrative' drugs.

Key words $\bullet$ coping strategy $\bullet$ elite-student-athletes $\bullet$ motivations $\bullet$ risky behaviours

Since the end of the 1980s, youth risky behaviours ('behaviours practised by young people that put their health at risk', CDC, 2002) have become a major issue for public health, and the scientific literature on this issue has quickly expanded. Many studies have attempted to assess whether or not various factors are 
linked to such behaviours, including family background, socioeconomic status, psychological disorders, and sporting activity.

Concerning the last topic, the literature remains controversial: according to several studies, young athletes have a healthier lifestyle than non-athletes (McArdle et al., 2000; Naylor et al., 2001; Pate et al., 2000), while other studies came to the opposite conclusion for drug use, risky driving or unsafe sex (Billet, 2001; Forman et al., 1995; Gonzalez et al., 1994; Sun et al., 2000). Among possible explanations, this inconsistency may be due to differences in definitions and measures of sporting activity and its context: institutionalized practice in a competitive setting should be distinguished from recreational physical exercise (Claeys, 1985; Lorenté, 2002; Thorlindsson, 1989).

One way to better assess the risky behaviour-sport relationship at adolescence is to focus on athletes with a homogeneous sporting background. We present here some results from a pilot survey focusing on elitestudent-athletes (ESAs) carried out in South-Eastern France. This survey gave us the opportunity to address three hypotheses concerning the relationship between sporting activity and risky behaviours :

- Sporting activity and risky behaviours may be impelled by similar motives and values (to get thrilled, to express commitment to masculine values). Indeed, as pointed out by psychologists (Csikszentmilhalyi, 1975; Zuckerman, 1979) and sociologists (Caillois, 1967; Lyng, 1990), both activities may reveal the same sensation-seeking, the same search for vertigo, exhilaration or 'flow'. This hypothesis is especially relevant to the relationship between sliding or ' $\mathrm{X}$-treme' sports and drug use in adolescence (Beck et al., 2000; Cherpitel et al., 1998; Pillard et al., 2001). Furthermore, in civilized societies, sport is one of the last strongholds (with some occupational spheres: army, police) for masculine values related to physical strength, aggressiveness and confrontation with opponents (Dunning, 1986; Sheard and Dunning, 1973). So athletes may be 'positive deviants', since they are socialized in a world that worships behaviours which are forbidden outside the sporting field (Coakley, 2001).

- Second, like any activity that allows youngsters to go out and escape temporarily from parental control, sporting practice may provide occasions to engage in risky behaviours with peers. This hypothesis refers to the opportunity structure of deviance, which is a classic subject in the sociology of deviance (Becker, 1963; Cloward and Ohlin, 1960). This topic has been extensively investigated for the relation between sport and juvenile delinquency, with contradictory results that highlighted the necessity for distinguishing organized and informal activities, and also for taking into account the level of competition (which could be linked to the degree of organization of sporting activity: coaches at higher level of play may exert more social control; Agnew, 1989; Schafer, 1969; Seagrave et al., 1985; Yiannikis, 1980).

- Lastly, drug use may be a means to alleviate the anxiety resulting from competition (Peretti-Watel et al., 2002a, 2002b). Indeed, competition frequently induces anxiety among young athletes (Bray et al., 2000; Passer, 1983; Smoll and Smith, 1990), and previous studies have already found that people use cigarettes, alcohol or cannabis to cope with stressors (Ballion, 2001; Holahan et al., 2001; Sorensen and Pechacek, 1987; Waldron, 1991).

\section{Method}

\section{Data Source}

The data were abstracted from the Survey on Elite Provençal Student-Athletes (SEPSA). The SEPSA survey is a pilot study, which is likely to be extended to the whole country in the years to come. In France, each year, the Ministry of Youth and Sports draws up three lists of the best young athletes and proposes that they enter specialized public centres administered at the regional level. The first list includes athletes who have already achieved significant performances in international competitions; the second list gathers 
young athletes with promising but not yet significant performances; the third one aims to supply athletes enlisted from the first two lists with valuable sparring partners. Each centre musters athletes practising the same sport, and organizes their training programmes, their school timetable, as well as their medical follow-up.

The SEPSA survey targeted ESAs aged 16-24 and registered in one of these three lists, in the centres located in South-Eastern France (Provence, the Alps and the French Riviera), which is placed third among French regions for the number of such centres. Among these centres, five were not included in the survey because their ESAs were either aged over 24 or under 16. The remaining 40 centres gathered 616 ESAs aged 16-24 in 28 different sports. Between February and May 2002, ESAs answered a self-administered questionnaire within a training room, in the presence of a professional investigator who was responsible for presenting the survey to the pupils. In order to ensure confidentiality, anonymous questionnaires were directly collected in a ballot box.

\section{Questionnaire}

The questionnaire included 127 closed-ended questions dealing with demographic background, mental health, sporting activity, lifestyle and opinions towards sport. ESAs were also asked to report their sporting discipline, but we did not use it. Indeed, the sample size by discipline was sometimes very small, thus using this variable in the analysis would have threatened respondents' anonymity.

Six so-called 'risky behaviours' were assessed by the questionnaire :

- Current smoking: subjects smoking cigarettes at the time of the study, at least from time to time (including both daily and less than daily smokers).

- Regular drinking: subjects drinking alcohol at least 10 times per month.

- Occasional use of cannabis: subjects smoking cannabis at least once during the last 12 months.

- Unsafe sexual intercourse: subjects having intercourse with a non-regular partner without using condom during the last 12 months.

- Drunk driving: subjects driving a vehicle while being drunk, at least once during the last 12 months.

- Non-use of seatbelt or helmet (for motorcycles): 'rarely', 'often', 'every time', versus 'never'.

In order to test whether or not sporting practice and risky behaviours were impelled by the same motives, the questionnaire included 12 questions dealing with ESAs' motivations to engage in sport (based on a four-point Likert scale). The potential influence of sporting peers on opportunities to behave in a risky way was measured by asking to respondents whether they had been out with athletes or with non-athletes during the last 30 days. Finally, the questionnaire included questions about psychological disorders which were measured with the GHQ-12 (General Health Questionnaire, 12-item version), a widely used instrument to detect psychological disorders, especially current depressive and anxiety symptoms. It has been validated in many countries, including France (Goldberg et al., 1997). In non-clinical populations, the GHQ-12 score is usually used as a continuous variable (Banks, 1983). This score ranges from 0 (no psychological disorder) to 36 (acute psychological disorders).

\section{Statistical Analysis}

We described our sample for male and female ESAs separately, using Pearson's 2 to compare them. Then, a cluster analysis was performed to summarize in some synthetic profiles the variety of motivations to engage in sport. For the corresponding 12 questions, items measuring agreement were encoded from 1 ('strongly disagree') to 4 ('strongly agree'). Non-responses were replaced by mean values, and the resulting variables were transformed to Z-scores prior to clustering. The cluster analysis was based on the agglomerative hierarchical procedure (each observation begins in a cluster by itself, then the two closest clusters are merged to form a new one, and this procedure is repeated until only one cluster is left). At every step, clusters were less homogeneous but more easily interpretable. We selected a three-cluster 
partition, which was described with $t$-tests for motivation items, an ANOVA test for age and GHQ-12, and Pearson's 2 for proportions (for gender, competitive level and outings).

We used multivariate logistic models to test the relationship between risky behaviours and motivations to do sport (with the three-cluster partition), outings with athletes or non-athletes, competitive level (national or regional versus international or Olympic), psychological disorders (GHQ-12 score), while controlling for usual confounding factors (gender and age). Our models were built by selecting step by step the more significant factors using the stepwise method (entry threshold $p=0.10$ ), with gender and age forced into all models. Odds ratios (ORs) were computed from the regression coefficients and their levels of statistical significance were computed from the Wald's 2. Given the small size of our sample, only one decimal is reported for ORs. By definition, ORs are equal to 1 for reference values.

Lastly, in the case of unsafe sexual intercourse, as previous studies showed that athletic participation and gender interact to influence adolescent sexual outcomes (Kokotailo et al., 1996; Miller et al., 1998, 2003; Sabo et al., 1999), two separate models were built: one for females, one for males.

\section{Results}

\section{Description of the Sample}

Among the 616 eligible ESAs, 147 were absent (most of them were on a sporting trip for a competition), 13 refused to participate or did not answer the demographic items and 458 (159 girls and 299 boys) completed the questionnaire correctly (response rate: $74.4 \%$ ).

As shown in Table 1, boys were slightly older than girls, and girls reported more symptoms of psychological disorders. One ESA out of two went in for competitive sport at the national level, and one out of three at the international or Olympic level. Concerning 'risky behaviours', boys were more prone to drink alcohol regularly, to use cannabis occasionally and to engage in unsafe road behaviour (drunk driving or non-use of seatbelt or helmet).

\section{Motivations to Engage in Sport}

The three-cluster partition summarizing motivations to engage sport is described in Table 2. Cluster 1 ( $n=$ $242,52.8 \%$ of the sample) corresponds to respondents who rated almost all items higher than other ESAs, except for motivations that refer to sport as leisure ('for pleasure', 'for health', 'to meet people, to make friends'). The highest scores for items related to personal and social achievement ('to become really someone', 'to feel strong', 'to earn money') were observed in this cluster, ahead of items related to sporting success. This profile of motives can be labelled as an instrumental orientation toward sport. Males were overrepresented among those respondents.

Respondents in Cluster 2 ( $n=103,22.5 \%$ of the sample) were characterized by high scores for items related to the competitive spirit ('performance', 'mounting the top of the rostrum', 'competition'), but they also highlighted the importance of pleasure.

These respondents were less prone to agree with motivations related to personal achievement ('to develop one's body', 'to feel strong', 'to become really someone', 'to earn money'). These ESAs were older and more prone to go out with other athletes or to go in for competition at the international or Olympic level. Finally, Cluster $3(n=113,24.7 \%)$ is characterized by higher scores for only two items ('pleasure', 'to meet people, to make friends'), and lower scores for items related to competitive spirit or personal and social achievement. Corresponding ESAs, who were more frequently females, who were younger and practised less frequently at the international or Olympic level, seemed to consider, above all, sport as a form of leisure.

\section{Factors Associated with Risky Behaviours among ESAs}

Once the effects of gender and age were controlled for, ESAs whose sporting practice was motivated by pleasure and sociability (sport as a form of leisure) were more prone to smoke cigarettes or to use cannabis occasionally, while those who considered sport as a means for personal and social achievement 
(instrumental orientation toward sport) were more likely to engage in unsafe road behaviour (drunk driving or non-use of seatbelt or helmet, OR $<1$ for Clusters 2 or 3 versus Cluster 1). Lastly, girls who endorsed the competitive spirit were more prone to engage in unsafe sex.

ESAs who went out recently with other athletes were more likely to be current smokers, regular drinkers (for boys only), or occasional users of cannabis. Those who went out with non-athletes were more prone to use cannabis occasionally, or to engage in unsafe sex (for boys only) or drunk driving.

Competition at the international or Olympic level was positively associated with current smoking and regular drinking (among boys only). Finally, psychological disorders were positively correlated with current smoking and occasional use of cannabis.

Lastly, as none of the three clusters is clearly oriented to thrill motivations, we directly tested the relationship between thrill motivations for sport and cannabis use in a separate model, by substituting the thrill motivation item for the three-cluster partition. We obtained no significant relationship between this item and cannabis use $(p=0.370)$.

\section{Discussion}

First, we have to acknowledge some limitations of our study. Data were extracted from a pilot survey carried out in only one French region, and must not be considered to represent a sample of the global French ESAs population (even if ESAs are recruited from the national level before being dispatched in regions according to the sport they practise). Moreover, because of the sample size, we did not separate systematically males and females in the analysis, nor take into account the heterogeneity of sporting disciplines.

Our first hypothesis was related to motives for practising sport and engaging in 'risky behaviours'. A cluster analysis on motivations reported by ESAs enabled us to identify three profiles. ESAs who considered sport as a leisure by emphasizing the importance of pleasure and sociability in sport were more likely to smoke cigarettes or cannabis (these two uses being closely connected), and we did not find the expected relationship between the search for thrills in sport and cannabis use. This result may illustrate the so-called 'normalization' of adolescent recreational drug use: most of the time, contemporary cannabis users are not daredevils, they do not consider themselves as risk-takers. They rather regard their consumption as convivial and safe leisure (Parker et al., 1998; Peretti-Watel, 2003). We also found that ESAs who were more prone to endorse motivations related to personal and social achievement, as well as motivations related to sporting success, were more likely to engage in risky behaviours on the road. The boundaries between the sporting field and the outside world may have become blurred for these ESAs who mixed sporting and non-sporting achievement: their propensity to risk-taking on the road could mean that they have transposed values from the sporting field (speed, competition) into the 'real world'. Lastly, among girls the competitive spirit was linked to unsafe sex, but this result should be interpreted cautiously because the corresponding subsample size is very small.

Second, we tried to address the topic of opportunities. Even if this hypothesis seems more relevant to the case of informal practice (Peretti-Watel et al., 2002a), our data illustrated the 'opportunity effect' for cannabis use: outings with athletes or non-athletes increased the risk of engaging in such use. But in the case of alcohol drinking among male ESAs, athletes who reported outings with athletes were more prone to drink regularly, while those who reported outings with non-athletes were not. This result points out the ambiguity of the 'opportunity effect'. Indeed, people are not passively exposed to their environment: they choose whether or not they jump at the opportunity, and they may also bring about the opportunity (Osgood et al., 1996). This observation relates to the first hypothesis about sporting socialization and masculine values perpetuated in 'male disciplines': outings with other athletes may provide an ESA with opportunities to drink alcohol, and he/she may jump at this opportunity because he/she has been socialized among peer athletes who value this behaviour. Previous studies have already observed a relationship between alcohol drinking and the practice of a 'male sport', like rugby or strength and combat sports (Peretti-Watel et al., 2002a; Quarrie et al., 1996). On the contrary, in our sample unsafe sex (for males only) and drunk driving were only related to outings with non-athletes. 
Third, competition frequently induces anxiety among young athletes, so drug use may be a means to alleviate this anxiety. The GHQ-12 score, assessing psychological disorders, and especially anxiety and depressive symptoms, was positively linked to current smoking and occasional use of cannabis, and ESAs who competed at the international or Olympic level were more prone to smoke cigarettes or (for males only) to drink alcohol regularly. Nevertheless, the GHQ-12 is probably a poor tool to assess anxiety among athletes: in the future, we should use sport-specific instruments. Moreover, the relationship between drug use and competition can also be interpreted with reference to the 'opportunity effect', since international competition means travelling abroad. Despite these empirical limitations, the relationsip between anxiety, competition and drug use illustrates the 'integrative' use of so-called 'recreational' drugs: they can be used to increase efficiency or simply to 'hold out' and to manage stress (Ehrenberg, 1991).

Lastly, further research is needed to improve the theoretical conceptualization of the relationship between sporting practice and so-called 'risky behaviours'. As both activities are frequently supposed to express common motives and values, we have to investigate what meaning the individual gives to his/her behaviours. Such a conceptualization should question the current definition of 'youth risky behaviours', because this definition merges deliberate risk-taking as well as behaviours that are not considered as

dangerous by those who engage in them. This is well-illustrated by cannabis use: we did not find the expected relationship between thrill motivations for sport and cannabis use, probably because adolescents do not experience this use as a search for thrills.

\section{Conclusion}

The SEPSA survey allowed us to study risky behaviours among a specific and homogeneous population of high-level young athletes, registered in public centres that provided them with a high standard of sporting facilities, training programmes and medical follow-up. We found some support for the tested hypotheses, even if some results could be interpreted in various ways: sporting activity and risky behaviours may be both impelled by similar motives and values; sporting activity may provide opportunities to engage in risky behaviours; 'recreational' drugs may be used as 'integrative' drugs, to alleviate the anxiety sharpened by competition.

Acknowledgements This study was supported by the Regional Council of South-Eastern France (Provence, the Alps and the French Riviera) and the Regional and Departmental Authority on Youth and Sports of South- Eastern France (DRDJS PACA).

\section{References}

Agnew, R. (1989) 'Leisure and Delinquency', Social Problems 36: 332-50. Ballion, R. (2001) Conduites délictueuses et consommation de substances psychoactives des lycéens (Delinquent Behaviours and Drug Use among High-School Students), report for the MAIF foundation and the French Monitoring Centre for Drugs and Drug Addictions (OFDT). Paris: MAIF.

Banks, M.H. (1983) 'Validation of the General Health Questionnaire in a Young Community Sample', Psychological Medicine 13: 349-53.

Beck, F., Legleye, S. and Peretti-Watel, P. (2000) View of the End of Adolescence: Uses of Psychoactive Products in the ESCAPAD 2000 Survey. Paris: OFDT.

Becker, H.S. (1963) Outsiders. New York: Free Press.

Billet, D., ed. (2001). Sports Played by Young People and Dangerous Behaviour. Paris: French Ministry of Youth and Sport.

Bray, S.R., Martin, K.A. and Widmeyer, W.N. (2000) 'The Relationship between Evaluative Concerns and Sport Competition State Anxiety among Youth Skiers', Journal of Sport Sciences 18: 353-61. 
Caillois, R. (1967) Les Jeux et les hommes: Le Masque et le vertige. Paris: Gallimard.

CDC (2002) Assessing Health Risk Behaviors among Young People: Youth Risk Behavior Surveillance System 2002. Atlanta, GA: Centers for Disease Control and Prevention.

Cherpitel, C.J., Meyers, A.R. and Perrine, M.W. (1998) 'Alcohol Consumption, Sensation Seeking and Ski Injury: A Case-Control Study’, Journal of Studies on Alcohol 59(2): 216-21.

Claeys, U. (1985) 'Evolution of the Concept of Sport and the Participation / Nonparticipation Phenomenon', Sociology of Sport Journal 2: 233-9

Cloward, R. and Ohlin, L. (1960) Delinquency and Opportunity. New York: Free Press.

Coakley, J. (2001) 'Deviance in Sports: Is it Out of Control?', in Sport in Society: Issues and Controversies. New York: McGraw Hill.

Csikszentmilhalyi, M. (1975) Beyond Boredom and Anxiety. San Francisco, CA: Jossey-Bass.

Dunning, E. (1986) 'Sport as a Male Preserve: Notes on the Social Sources of Masculinity and its Transformations', in N. Elias and E. Dunning (eds) Quest for Excitement: Sport and Leisure in the Civilizing Process. Oxford: Blackwell.

Ehrenberg, A. (1991) Le Culte de la performance. Paris: Calmann-Lévy.

Forman, E.S., Dekker, A.H., Javors, J.R. and Davison, D.T. (1995) 'High-Risk Behaviors in Teenage Male Athletes', Clinical Journal of Sport Medicine 5(1): 36-42.

Goldberg, D.P., Gater, R., Sartorius, N., Ustun, T.B., Piccinelli, M., Gureje, O. and Rutter, C. (1997) 'The Validity of Two Versions of the GHQ in the WHO Study of Mental Illness in General Health Care', Psychological Medicine 27: 191-7.

Gonzalez, J., Field, T., Yando, R., Gonzalez, K., Lasko, D. and Bendell, D. (1994) 'Adolescents' Perceptions of their Risk-Taking Behavior', Adolescence 29(115): 701-9.

Holahan, C.J., Moos, R.H., Holahan, C.K., Cronkite, R.C. and Randall, P.K. (2001) 'Drinking to Cope, Emotional Distress and Alcohol Use and Abuse: A Ten-Year Model', Journal of Studies on Alcohol 62: 190-8.

Kokotailo, P.K., Henry, B.C., Koscik, R.E., Fleming, M.F. and Landry, G.L. (1996) 'Substance Use and Other Health Risk Behaviors in Collegiate Athletes', Clinical Journal of Sport Medicine 6(3): $183-9$.

Lorenté, F. (2002) 'Sports Involvement can be Both Formal and Informal at the Same Time: A Comment on Peretti-Watel et al.', Addiction 97: 1607.

Lyng, S. (1990) 'Edgework: A Social Psychological Analysis of Voluntary Risk Taking', American Journal of Sociology 95: 851-66.

McArdle, P., Wiegersma, A., Gilvarry, E., McCarthy, S., Fitzgerald, M., Kolte, B., Brinkley, A., Blom, M., Stoeckel, I., Pierolini, A., Michels, I., Johnson, R. and Quensel, S. (2000) 'International Variations in Youth Drug Use: The Effect of Individual Behaviours, Peer and Family Influences, and Geographical Location', European Addiction Research 6(4): 161-2.

Miller, K.E., Sabo, D.F., Farrell, M.P., Barnes, G.M. and Melnick, M.J. (1998) 'Athletic Participation and Sexual Behavior in Adolescents: The Different Worlds of Boys and Girls', Journal of Health and Social Behavior 39: 108-23.

Miller, K.E., Barnes, G.M., Melnick, M.J., Sabo, D.F. and Farrell, M.P. (2003) 'Gender and Racial/Ethnic Differences in Predicting Adolescent Sexual Risk: Athletic Participation versus Exercise', Journal of Health and Social Behavior 43(4): 436-50.

Naylor, A.H., Gardner, D. and Zaichkowsky, L. (2001) 'Drug Use Patterns among High School Athletes and Nonathletes', Adolescence 36: 627-39.

Osgood, D.W., Wilson, J.K., O’Malley, P.M., Bachman J.G. and Johnston, L.D. (1996) 'Routine Activities and Individual Deviant Behavior', American Sociological Review 61: 635-55.

Parker, H., Alridge, J. and Measham, F. (1998) Illegal Leisure: The Normalization of Adolescent Recreational Drug Use. London: Routledge.

Passer, M.W. (1983) 'Fear of Failure, Fear of Evaluation, Perceived Competence, and Self-Esteem in Competitive-Trait-Anxious Children', Journal of Sport Psychology 5: 172-88. 
Pate, R.R., Trost, S.G., Levin, S. and Dowda, M. (2000) 'Sports Participation and Health-Related Behaviors among US Youth', Archives of Pediatrics and Adolescence Medicine 154: 904-11.

Peretti-Watel, P. (2003) 'Neutralisation Theory and Denial of Risk: Some Evidences from Cannabis Use among French Adolescents', British Journal of Sociology 54(1): 21-42.

Peretti-Watel, P., Beck, F. and Legleye, S. (2002a) 'Beyond the U-Curve: The Relationship between Sport and Alcohol, Cigarette and Cannabis Use in Adolescents', Addiction 97: 707-16.

Peretti-Watel, P., Beck, F. and Legleye, S. (2002b) 'More about Sport and Drug Use: Context, Competition and "Integrative Drugs", Addiction 97: 1609-11.

Pillard, F., Cances-Lauwers, V., Godeau, E., Navarro, F., Rolland, Y. and Riviere, D. (2001) 'Sport Practice and Cannabis Consumption in a Representative Sample of French High School Adolescents', Annales de Médecine Interne 152(S7): 28-36.

Quarrie, K.L., Feehan, M., Waller, A.E., Cooke, K.R., Williams, S. and McGee, R. (1996) 'The New Zealand Rugby Injury and Performance Project: Alcohol Use Patterns within a Cohort of Rugby Players', Addiction 91: 1865-8.

Sabo, D.F., Miller, K.E., Farrell, M.P., Melnick, M.J. and Barnes, G.M. (1999) 'High School Athletic Participation, Sexual Behavior and Adolescent Pregnancy: A Regional Study', Journal of Adolescent Health 25(3): 207-16.

Schafer, W. (1969) 'Some Social Sources and Consequences of Inter-Scholastic Athletics: The Case of Participation and Delinquency', International Review of Sport Sociology 4: 63-81.

Seagrave, J., Moreau, C. and Hastad, D.N. (1985) 'An Investigation into the Relationship between Ice Hockey Participation and Delinquency', Sociology of Sport Journal 2: 281-98.

Sheard, K. and Dunning, E. (1973) 'The Rugby Football Club as a Type of Male Preserve: Some Sociological Notes', International Review for the Sociology of Sport 5: 5-24.

Smoll, F.L. and Smith, R.E. (1990) 'Psychology of the Young Athlete, Stress-Related Maladies and Remedial Approaches', Sports Medicine 37(5): 1021-46.

Sorensen, G. and Pechacek, T.F. (1987) 'Attitudes toward Smoking Cessation among Men and Women', Journal of Behavioral Medicine 10: 129-37.

Sun, C., Dyck, D. and Guillory, V. (2000) 'The Impact of School-Organized Sport Activities on the Priority Youth Health-Risk Behaviors', Annals of Epidemiology 10(7): 451-2.

Thorlindsson, T. (1989) 'Sport Participation, Smoking, and Drug and Alcohol Use among Icelandic Youth', Sociology of Sport Journal 6: 136-43.

Waldron, I. (1991) 'Patterns and Causes of Gender Differences in Smoking', Social Science and Medicine 32: $989-1005$.

Yiannikis, A. (1980) 'Sport and Deviancy: A Review and Appraisal', Motor Skins: Theory into Practice 4: 59-64.

Zuckerman, M. (1979) Sensation Seeking. Hillsdale, NJ: Lawrence Erlbaum. 


\section{Tables}

Table 1 Description of the SEPSA Subjects: Age, Psychological Disorders, Outings, Competitive Level and 'Risky Behaviours' According to Gender

\begin{tabular}{lllll}
\hline & $\begin{array}{l}\text { Girls }(\%) \\
n=159\end{array}$ & $\begin{array}{l}\text { Boys }(\%) \\
n=299\end{array}$ & $p^{*}$ & $\begin{array}{l}\text { Total }(\%) \\
n=458\end{array}$ \\
\hline Average age (in years) (SD) & $18.0(2.1)$ & $18.5(2.3)$ & $<.05$ & 18.3 \\
GHQ-12 average score (SD) & $15.2(6.9)$ & $11.3(5.3)$ & $<.001$ & 12.2 \\
Outings during the last 30 days** & & & & \\
$\quad$ with athletes $(n=338)$ & 73.6 & 73.9 & .939 & 73.8 \\
$\quad$ with non-athletes $(n=322)$ & 72.3 & 69.2 & .490 & 70.3 \\
Competitive level & & & & \\
$\quad$ regional $(n=70)$ & 10.7 & 17.7 & .962 & 15.3 \\
$\quad$ national $(n=236)$ & 56.0 & 49.2 & & 51.5 \\
$\quad$ international, Olympic $(n=152)$ & 33.3 & 33.1 & & 33.2 \\
& & & & \\
'Risky behaviours': & & & & \\
$\quad$ current smoking $(n=105)$ & 24.5 & 22.1 & .552 & 22.9 \\
$\quad$ regular drinking $(n=27)$ & 0.6 & 8.7 & $<.001$ & 5.9 \\
occasional use of cannabis $(n=111)$ & 18.2 & 28.2 & $<.05$ & 24.7 \\
$\quad$ unsafe sexual intercourse $(n=47)$ & 8.2 & 11.4 & .283 & 10.3 \\
drunk driving $(n=93)$ & 12.6 & 24.7 & $<.01$ & 20.3 \\
non-use of seatbelt or helmet $(n=141)$ & 21.4 & 35.8 & $<.001$ & 30.8 \\
\hline
\end{tabular}

* p-value for testing the independehce hypothesls between Inales and fernales for each row varlable.

*** the two Iterns were hot exclusive. 
Table 2 Cluster Analysis on Motivations to Do Sport among ESAs, Description by Gender, Age and Sporting Characteristics

\begin{tabular}{|c|c|c|c|c|}
\hline & $\begin{array}{l}\text { Cluster } 1 \\
n=242\end{array}$ & $\begin{array}{l}\text { Cluster } 2 \\
n=103\end{array}$ & $\begin{array}{l}\text { Cluster } 3 \\
n=113\end{array}$ & $\begin{array}{l}\text { Total } \\
n=458\end{array}$ \\
\hline \multicolumn{5}{|l|}{ Motives to do sport (mean*): } \\
\hline For pleasure & 3.6 & 4.0 & 4.0 & 3.8 \\
\hline For performance & 3.8 & 3.9 & 3.0 & 3.6 \\
\hline For health & 3.2 & 2.7 & 3.2 & 3.1 \\
\hline To feel strong & 3.0 & 2.0 & 2.0 & 2.5 \\
\hline To meet people, to make friends & 2.8 & 2.5 & 3.2 & 2.8 \\
\hline For competition & 3.8 & 3.8 & 3.0 & 3.6 \\
\hline To become really someone & 3.2 & 2.1 & 1.9 & 2.6 \\
\hline To be thrilled & 3.6 & 3.4 & 3.1 & 3.4 \\
\hline To develop one's body & 3.3 & 2.6 & 2.9 & 3.1 \\
\hline To earn money & 2.3 & 1.5 & 1.5 & 1.9 \\
\hline To mount the top of the rostrum & 3.7 & 3.6 & 2.3 & 3.3 \\
\hline Because one's parent(s) practised sport & 1.9 & 1.3 & 1.6 & 1.7 \\
\hline \multicolumn{4}{|l|}{ Description of clusters: } & $p^{* *}$ \\
\hline Female & $29.3 \%$ & $34.0 \%$ & $46.9 \%$ & \multirow[t]{2}{*}{$<05$} \\
\hline Male & $70.7 \%$ & $66.0 \%$ & $53.1 \%$ & \\
\hline Average age (in years) (SD) & $18.2(2.2)$ & $19.0(2.4)$ & $17.9(2.0)$ & $<01$ \\
\hline GHQ-12 average score (SD) & $12.5(6.6)$ & $12.8(5.6)$ & $12.9(6.1)$ & .833 \\
\hline \multicolumn{5}{|l|}{ Outings during the last 30 days } \\
\hline with athletes & $74.8 \%$ & $80.6 \%$ & $65.5 \%$ & $<05$ \\
\hline with non-athletes & $66.9 \%$ & $75.7 \%$ & $72.6 \%$ & .219 \\
\hline \multicolumn{5}{|l|}{ Competitive level } \\
\hline regional, national & $66.2 \%$ & $58.3 \%$ & $74.3 \%$ & \multirow[t]{2}{*}{$<05$} \\
\hline international, Olympic & $33.1 \%$ & $41.7 \%$ & $25.7 \%$ & \\
\hline
\end{tabular}

* Iterns Ineasurling agreernent were ehcoded fiorn I ('strongly disagree') to 4 ('strongly agree'). For each Itern, $t$-tests were computed to compare each cluster to the rest of the sample. For each cluster, the Inost signiflcaht Iterns $(p<.001$ ) were in bold type (for Iterns with a higher value within the cluster) or in italics (for Iterns with a lower value within the cluster).

*** p-value for testing the Independence hypothesis between the four-cluster partition and each row varlable. 


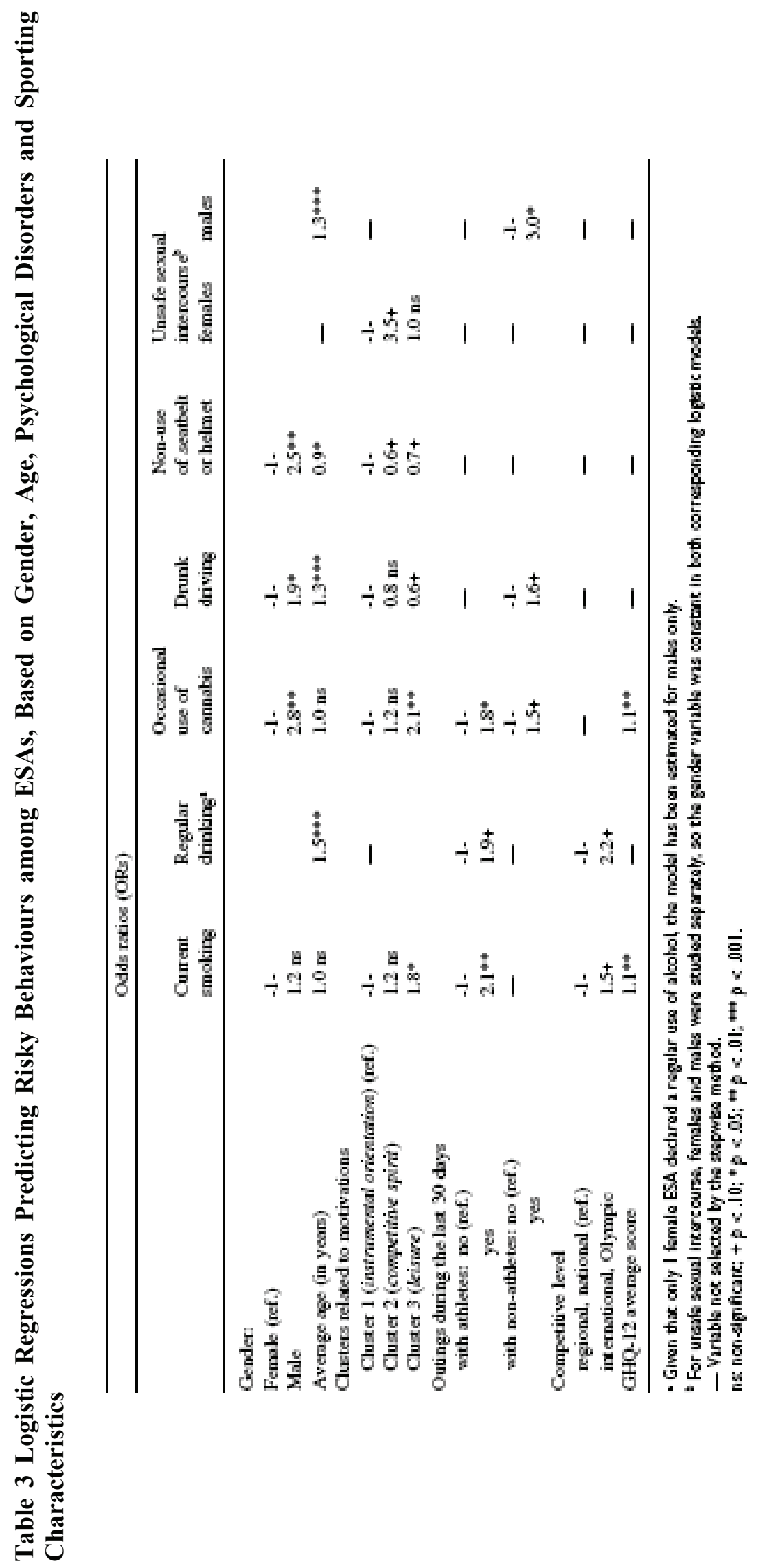

